\title{
Conceptual structure, information load and perceptual complexity'
}

SIEGFRIED STREUFERT, RUTGERS, THE STATE UNIVERSITY ${ }^{2}$ MICHAEL J. DRIVER, PURDUE UNIVERSITY

\begin{abstract}
A simulated decision making environment was used to test certain theoretical propositions of Schroder, Driver \& Streufert (in press). It was shown that differentiation and integration in perception increases with increasing information load until a criterion of optimal perception is reached. Beyond this optimal point, differentiation and integration in perception decreases with further increasing information load. These findings may be represented as an inverted U shaped curve relating load and perception. Differences in the conceptual structure of Ss resulted in different levels of this inverted $U$ curve. The results parallel a similar study of Streufert \& Schroder (in press) concerned with differentiation and integration in performance.
\end{abstract}

\section{Problem}

Schroder, Driver \& Streufert (in press) have postulated a family of $U$ shaped curves relating environmental input to cognitive and behavioral properties. These curves have some similarity to those of arousal theory formulations (Hebb, 1955), and the propositions of Fiske \& Maddi (1963). In explaining the curves, Schroder et al propose that differentiation and integration in cognition and behavior increases with increasing environmental input until an optimal information processing level is reached. If environmental input increases further, the information processing level should begin to decrease. Differing individual curves are proposed to represent differences in the conceptual structure of the individuals or groups observed.

In an experiment using four man decision making teams in a complextask, Streufert \& Schroder (in press) have confirmed the Schroder et al (in press) hypothesis for the effect of information load (a component of environmental input) on differentiation and integration in decision making performance. The experiment discussed here employs the same independent variables and method used by Streufert and Schroder, but substitutes measurement of differentiation and integration in perception for differentiation and integration in performance as its dependent variable. It represents a further test of the Schroder et al theory.

\section{Subjeets}

Two hundred and thirty-six male students of three eastern universities and colleges were tested to determine their level of conceptual structure. Tests utilized were the Sentence Completion Test (Schroder \& Streufert, 1963) and the Impression Formation Test (Streufert \& Schroder, 1963). Eighty Ss were selected on the basis of very low (40 Ss) or very high (40 Ss) scores on these tests. Mean differences between SAT verbal and quantitative scores of the two groups were small and non-significant. Twenty structurally homogenous four man teams were formed.

\section{Procedure}

Teams were placed in a tactical game situation (see Streufert, Clardy, Driver, Karlins, Schroder \& Suedfeld, in press). Each team was given the task of making decisions regarding the invasion of a mythical island. Ss were under the impression that they were playing against another defending team. However, all functions of the enemy team were performed by Es. The strategy played by the supposed enemy team was preprogrammed. The constant strategy and the design of the island assured that all teams could be kept approximately equal in (a) the general kind of operations employed by them, and (b) their level of success (teams were moderately successful at all times).

All teams were exposed to seven different information load conditions. During each 1/2-hr. game period, Ss received either $2,5,8,10,12,15$, or 25 independent informative statements. The order of these load periods was varied at random. Ten different load sequences were used. Each sequence was employed for one team of Ss scoring high and one team of Ss scoring low on the measures of conceptual structure.

All seven game periods were played during a single evening. After each playing period was completed, Ss were instructed to fill out "commander reports" as individuals. Group members did not interact during these "intermissions." Among the questions asked were the following: (a) describe the strategy which you believe the enemy team is using, (b) how does this strategy relate to enemy activity, (c) is there any effect of your actions on enemy strategy, (d) what has made the enemy's strategies appear reasonable to him, and (e) comment on the possible consequences of the enemy's strategies for your side and for his side.

A number of scoring categories, derived from the Schroder et al (in press) theory, were developed to measure differentiation and integration in perception. These categories are (1) cause effect descriptions involving interrelated actions of S's own and the opposing team, (2) inferences from observations involving three or more steps, (3) descriptions of long term intentions of the opposing team, relating present activity to those intentions, and (4) responses generally identified as "empathic." The responses of all $40 \mathrm{Ss}$ to the above questions were scored according to these categories. 


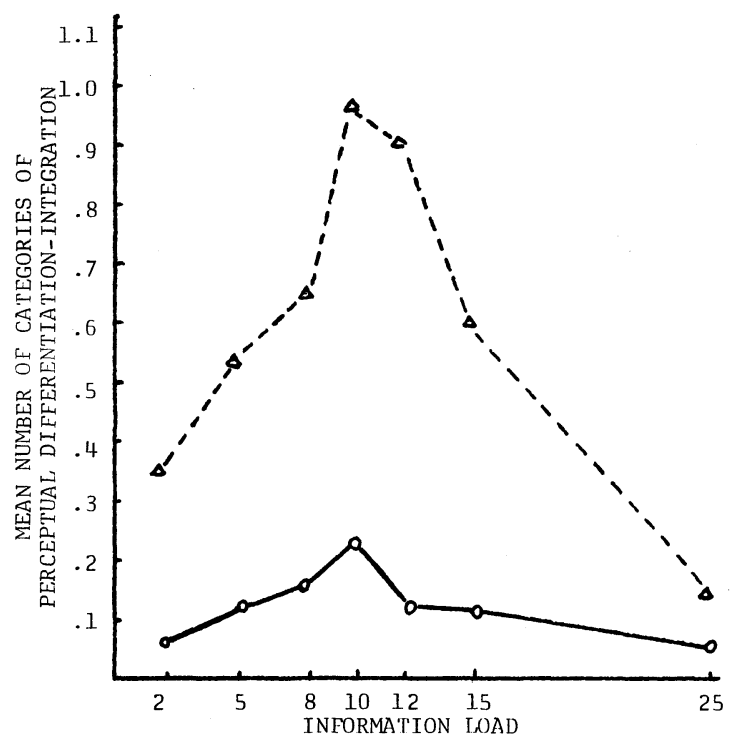

Fig. 1. Mean number of categories of perceptual differentiationintegration for Ss under different information load conditions.

Inter-rater reliability for four raters ranged from .89 to .96 . Average frequency of occurrence of each category was: Category $1, \mathrm{M}=.18$ for low scores and $M=1.15$ for high scorers; Category $2, M=.25$ for low scorers and $M=.83$ for high scorers; Category 3 , $M=.20$ for low scorers and $M=1.20$ for high scorers; and Category $4, M=.25$ for low scorers and $M=.93$ for high scorers.

\section{Results and Diseussion}

A Lindquist Type I Analysis of variance (Lindquist, 1953) was used to test for significance. The main effects for information load and for conceptual structure are significant $(p<.01$ for the information load effect, and $p<.01$ for the conceptual structure effect). The interaction effect is not significant. The results of the data analysis are presented in Fig. 1. Load conditions are plotted on the abscissa, the mean number of categories of perceptual differentiation-integration scores are plotted on the ordinate. Perceptual integration for all Ss increases as information load increases from 2 to 10 independent informing statements, and decreases as information load further increases from 10 to 25 independent informing statements. Persons scoring high on measures of conceptual structure score higher on the number of perceptual integration categories.
The results found here for perception are highly similar to the results of Streufert \& Schroder (in press) with performance characteristics. One difference however, appears clearly: an inspection of the curves produced by the two experiments indicates that the curve peak of high scorers for differentiation and integration in performance is considerably more pronounced than the equivalent peak in perception. A number of possible reasons for this observation suggest themselves: (1) measurement of differentiation and integration in perception as employed here may be much less complete than the same measurement in performance, (2) differentiation and integration capacities of individuals may sum so that groups produce much higher differentiation and integration levels under optimal conditions than individuals would, and (3) differentiation and integration in performance may be in part due to self-generated information (cf Lanzetta, 1963) which can be utilized for differentiation and integration in performance but does not appear in responses to questions intended to measure differentiation and integration in the perception of environmental characteristics.

\section{References}

Fiske, D. W., \& Maddi, S. R. Functions of varied experience. Homewood, Ill: Dorsey Press, 1961.

Hebb, D. O. Drives and the CNS. Psychol. Rev., 1955, 62, 243-254. Lanzetta, J. T. Information acquisition in decision making. In O. J. Harvey (Ed.), Motivation and social interaction. New York: Ronald Press, 1963.

Lindquist, E. F. Design and analysis of experiments in psychology and education. Boston: Houghton Mifflin, 1953.

Schroder, H. M., Driver, M. J., \& Streufert, S. Information processing systems in individuals and groups. New York: Holt, Rinehart and Winston, in press.

Schroder, H. M., \& Streufert, S. The measurement of four systems of personality structure varying in levels of abstractness: sentence completion method. Princeton University: ONR Tech. Rep., 1963.

Streufert, S., Clardy, M. A., Driver, M. J., Karlins, M., Schroder, H. M., \& Suedfeld, P. A tactical game for the analysis of complex decision making in individuals and groups. Psychol. Rep., in press.

Streufert, S., \& Schroder, H. M. Conceptual structure, environmental complexity and task performance. J. exp. Res. Pers., in press.

Streufert, S., \& Schroder, H. M. The measurement of four systems of personality structure varying in level of abstractness: impression formation method. Princeton University: ONR Tech. Rep., 1963.

\section{Noter}

1. This research was supported by the Research Council, Rutgers, The State University

2. Douglass College 